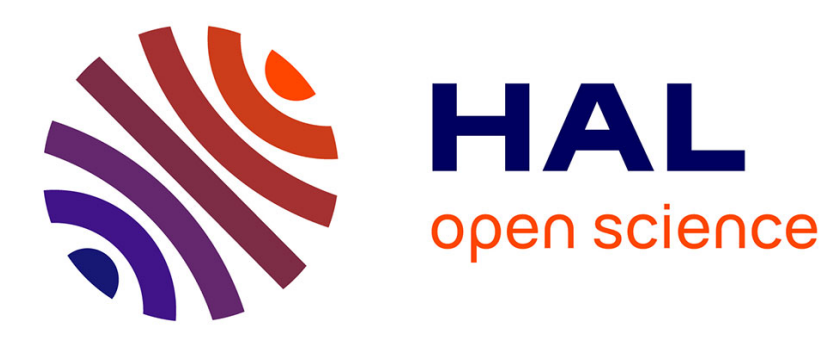

\title{
The quality effect of intrafirm bargaining with endogenous worker flows
}

\author{
Tristan-Pierre Maury, Fabien Tripier
}

\section{To cite this version:}

Tristan-Pierre Maury, Fabien Tripier. The quality effect of intrafirm bargaining with endogenous worker flows. 2011. hal-00566168v2

\section{HAL Id: hal-00566168 \\ https://hal.science/hal-00566168v2}

Preprint submitted on 13 Jul 2012

HAL is a multi-disciplinary open access archive for the deposit and dissemination of scientific research documents, whether they are published or not. The documents may come from teaching and research institutions in France or abroad, or from public or private research centers.
L'archive ouverte pluridisciplinaire HAL, est destinée au dépôt et à la diffusion de documents scientifiques de niveau recherche, publiés ou non, émanant des établissements d'enseignement et de recherche français ou étrangers, des laboratoires publics ou privés. 


\title{
The quality effect of intrafirm bargaining with endogenous worker flows*
}

\author{
Tristan-Pierre Maury ${ }^{\dagger} \quad$ Fabien Tripier ${ }^{\ddagger}$
}

July 13, 2012

\begin{abstract}
This paper proposes a new explanation of the job quality issue in search and matching models, which is not based on market externalities but on strategic interactions within firms through the intrafirm bargaining process. We develop a matching and intrafirm bargaining model in which large firms hire workers on a frictional labour market and decide to destroy low productivity job-worker matches. The coexistence of entry and exit flows of workers in a large firm gives rise to a specific interaction between the firing decision and the intrafirm bargaining process on wages, which causes inefficient decisions to be made on hiring and firing. The sources of inefficiency in this economy are (i) the well-known quantitative effect of intrafirm bargaining, namely the excessive size of the firms concerned, and (ii) a new quality effect, namely the poor quality of the job-worker matches selected by firms.
\end{abstract}

Keywords: Matching; Intrafirm Bargaining; Worker Flows.

JEL Classification: J3; J6.

${ }^{*}$ We thank Giuseppe Bertola, Pierre Cahuc, William Hawkins, Philipp Kircher and the participants of the inaugural conference of the European Search and Matching (SaM) network at the University of Bristol (2011). The usual disclaimers apply.

${ }^{\dagger}$ EDHEC Business School, Economic Research Centre, Email: tristan.maury@edhec.edu

${ }^{\ddagger}$ University of Nantes, Lemna, Email: fabien.tripier@univ-nantes.fr 


\section{Introduction}

The quality of jobs is a highly debated topic in labor economics from both empirical and theoretical perspectives. The empirical debate started in the eighties, when some economists, as Bluestone and Harrison (1988), have warned of the rising number of low-quality jobs; see Goos and Manning (2007) for an recent assessment of this view. The theoretical debate has focused on the ability of the competitive market to provide the efficient quality of jobs. The seminal contributions of Stevens (1994), Redding (1996) and Acemoglu (2001) showed that the quality of jobs is generally inefficient with labor market search frictions because of market externalities. ${ }^{1}$ In this paper, we provide a new explanation of the bias toward low-quality jobs, which is not based on market externalities but on the intrafirm bargaining mechanism described by Stole and Zwiebel (1996ab). ${ }^{2}$ The bias toward low-quality jobs is the outcome of the strategic interactions within firms between the bargaining process on wages with workers and the selection of the quality of worker-job matches by firms. This result is obtained by extending the matching and intrafirm bargaining literature initiated by Smith (1999), Cahuc and Wasmer (2002) and Cahuc et al. (2008) to the case of endogenous workers flows of entry and exit in firms. ${ }^{3}$

The empirical literature on labour market flows has highlighted the importance of workers flows and of its distinction with job flows. Job flows are associated with the net variation in the mass of jobs at the establishment level: job destruction only occurs in contracting establishments, in which the total mass of jobs falls, while job creation only occurs in expanding establishments, in which the total mass rises,

\footnotetext{
${ }^{1}$ Stevens (1994) considers externalities between firms in the provision of on-the-job training and Redding (1996) pecuniary externalities between investments in human capital (by workers) and in R\&D (by firms). In Acemoglu (2001), pecuniary externalities are the result of an hold-up phenomena associated with the choice of capital by firms.

${ }^{2}$ Stole and Zwiebel (1996ab) develop a general setup to study the joint decisions on wages and on the organization of firms and describe the inefficiencies induced by the strategic interactions between these decisions.

${ }^{3}$ The job destruction process is exogenous in Smith (1999), Cahuc and Wasmer (2002) and Cahuc et al. (2008). The firms' training effort in matching and intrafirm bargaining models is studied by Tripier (2011), but still with exogenous job destruction. Matching and intrafirm bargaining models with endogenous firms dynamics are presented and discussed below.
} 
see Davis and Haltiwanger (1990). Job creation and job destruction cannot simultaneously occur within establishments, and only establishments heterogeneity can permit the reallocation of jobs. The picture is somewhat different for worker flows because the entry and exit of workers may take place simultaneously in firms. Among others, Burgess et al. (2000) demonstrated that worker flows largely exceed job flows, and that regardless of its size or the growth in its number of employees, entry and exit worker flows occur simultaneously in most establishments. ${ }^{4}$ We develop a matching and bargaining model consistent with this specificity of worker flows (i.e., that entry and exit flows occur simultaneously within firms) and use this model to assess the potential inefficiencies in the quantity and the quality of the job-worker matches in the labour market.

In order to study worker flows within large firms, we cannot use the traditional matching and bargaining model of the labour market developed by Diamond (1982), Pissarides (2000), and Mortensen and Pissarides (1994), in which firms are small and composed of one single job. ${ }^{5}$ We must instead consider the decisions of large firms composed of heterogeneous job-worker matches. Jobs and workers are homogeneous, but when they are matched, the effective productivity of each job-worker pair is subject to idiosyncratic productivity shocks. It is widely-known that considering large firms with a non trivial production function (i.e., a concave technology) has strong normative implications. While there exists a condition of efficient bargaining when firms are small ${ }^{6}$, the wage negotiation is generally inefficient in large firms. It proceeds from the strategic interactions between the firm's decisions on the organisational design of production and the processes of wage bargaining with workers originally described by Stole and Zwiebel (1996a,b) and known as intrafirm bargaining. One of their key findings was that intrafirm bargaining causes firms to overemploy workers in order to reduce their individual marginal productivities, thereby reducing the individual wage

\footnotetext{
${ }^{4}$ These facts have been updated and confirmed for the US economy by Davis et al. (2006) who combine the most recent datasets including the Job Openings and Labor Turnover Survey.

${ }^{5}$ Kiyotaki and Lagos (2007) and Burgess and Turon (2010) make the distinction between job flows and worker flows in matching models with small firms by assuming that a job can survive after a separation with a worker and be filled with another worker.

${ }^{6}$ The efficient labour contract of Hosios (1990) and Pissarides (2000) has been defined in matching models with small firms.
} 
bargained with each worker. Smith (1999), Cahuc and Wasmer (2001), and Cahuc et al. (2008) all studied the effects of intrafirm bargaining on hiring in the matching model. ${ }^{7}$ Our aim herein is to extend this literature to the case of endogenous worker reallocation driven by hiring and firing. Because the firing decision endogenises the average quality of the job-worker matches in firms, we can identify a new qualitative effect of intrafirm bargaining in addition to the traditional quantitative effect associated with the size of firms.

The novelty of our approach lies in the decision to address the issue of intrafirm bargaining in a setup where firms simultaneously hire and fire workers. This is in contrast with the literature that has considered the issue of intrafirm bargaining in models of heterogeneous firms that either create or destroy jobs in the tradition of Bertola and Caballero (1994), such as for example, Bertola and Garibaldi (2001), Koeniger and Prat (2007), Fujita and Nakajima (2009), Cosar et al. (2010), and Elsby and Michaels (2010). In such models, contracting firms destroy jobs when hit by an adverse idiosyncratic shock that causes a drop in the demand of labour. An important property of this type of model is that workers in contracting firms are unable to extract a positive rent from the Nash bargaining program on wages because the marginal value of a job is zero or negative for the firm. The wage is consequently set at the worker's reservation level that makes its utility equal to that of an unemployed worker. Therefore, wages in contracting firms are independent of the decisions of firms and there is no room for strategic interactions between the firing decision and wage bargaining.

For worker flows, because firms simultaneously hire and fire workers, our setup allows new interactions to take place between the firing decision and wage bargaining. Existing matching models with large firms that simultaneously hire and fire workers ${ }^{8}$ are not suitable for our purposes because they generally assume a trivial production technology, with a constant marginal productivity of labour, which makes the individual

\footnotetext{
${ }^{7}$ The strategic interaction between the firm's decision on job creation and the wage bargaining process leads firms to post an excessive number of vacancies or equivalently to overhire workers.

${ }^{8}$ See in particular Merz (1999), Krause and Lubik (2007), Krause et al. (2008), and Faia et al. (2010). In Faberman and Nagypal (2008), the recruitment technology is non-linear (the marginal cost of creation of positions is increasing), but the production technology is linear with a constant marginal productivity of labor.
} 
wage independent of the firm's decisions and as a result removes the strategic interactions from the model. The only exception is Helpman et al. (2010) who studied the consequences of globalisation in a model where heterogeneous firms screen workers. ${ }^{9}$ We depart from several assumptions of Helpman et al. (2010). First, while we assume perfect competition on the goods market, they consider imperfect competition, hence intrafirm bargaining is the only source of inefficiency in our setup. Second, we solve a dynamic rather than a static labour market search model. Third, we consider idiosyncratic productivity of matches at the origin of firing instead of the screening technology introduced by them. Fourth, we model explicitly the utility of unemployed workers, which they normalize to zero. This last point matters because at equilibrium, the labour market tightness affects wages through the endogenous value of unemployed worker utility.

In our model, we have brought together several different strands of the literature on matching and bargaining models. The process of hiring is modelled as in the standard matching model of the labour market; e.g., Pissarides (2000). Firms post costly vacancies on the labour market and unemployed workers search passively for a job. An aggregate matching function determines the flow of new hirings according to the masses of vacancies and unemployed workers. The worker-job matches destruction process is taken from den Haan et al. (2000). The productivity of matches is heterogeneous due to the presence of non persistent idiosyncratic shocks. ${ }^{10}$ The distribution of productivity is the same for newly created matches and for existing ones. If the match productivity is too low, the worker is fired by the firm, corresponding to the endogenous firing carried out by firms. Domestic production for unemployed workers ensures that temporary layoff are not preferred to permanent layoff. In addition, there is an exogenous firing rate in firms that is independent of the match productivity. This structure of shocks was considered by den Haan et al.

\footnotetext{
${ }^{9}$ Fujita and Nakajima (2009) develop a business cycle model with both worker flows and job flows, but since separations are exogenous there is no room for the strategic interactions between the firing decision and wage bargaining considered in this paper.

${ }^{10}$ Considering persistent idiosyncratic shocks would clearly be a more realistic assumption, but that would complicate the analytics of the model making the identification and the interpretation of the strategic interpretation between firing and wage bargaining more difficult .
} 
(2000) in a model applied to small firms. We follow the approach of Krause and Lubik (2007), who applied the same structure of shocks for large firms, but contrary to these authors, we consider a non-constant marginal productivity of labour. The concavity of the production technology gives rise to the intrafirm bargaining issue. The process of bargaining on wages is solved using the solution proposed by Cahuc et al. (2008) for matching and intrafirm bargaining models. As in Cahuc et al. (2008), there is no firm entry. ${ }^{11}$

We show that intrafirm bargaining induces inefficient hiring and firing rules in the economy. The individual wage solution of the intrafirm bargaining process depends on two variables that are decided by the firm, namely its quantity of matches and its reservation productivity. In the intrafirm bargaining setup, the firm tries to increase its profits by reducing workers' productivity in order to push down the bargained wages. In our setup, the firm has two means of reaching this aim: it can either increase the quantity of matches or decrease their average quality. The former is common in the intrafirm bargaining literature, whereas the second is new and specific to our setup of workers flows. To lower the average wage, the representative firm seeks to increase its production by posting a number of vacancies that is too high (as in other models of intrafirm bargaining and matching) and by choosing a level of reservation productivity that is too low (this effect is specific to our setup). We use numerical simulations to quantify the effects of intrafirm bargaining. For our benchmark calibration, intrafirm bargaining induces an excess supply of vacancies and an insufficient quality of matches. This result is in the line with the classical overemployment result of Stole and Zwiebel (1996a,b). Our model shows that with endogenous firing, overemployment is the outcome of an excessive supply of vacancies and a firing rate that is too low. The source of inefficiency in this economy is not only the excessive size of firms, but also the poor quality of the jobs selected by them.

The remainder of our article is organised as follows. We describe our model in section 2 and in section 3 , we show the resolution of the intrafirm bargaining process on wages, and give a formal definition of the equilibrium and its normative properties. In section 4, we provide some brief conclusions.

\footnotetext{
${ }^{11}$ Smith (1999) proposes a model with an endogenous entry of firms on the markets.
} 


\section{The Model}

\subsection{Hiring, Firing, and Production}

In our model, firms are composed of an endogenous number of job-worker matches, which are subject to idiosyncratic productivity shocks that are denoted $a$. At the beginning of each period, existing and newly formed matches draw a value for $a$ from the cumulative distribution function $G(\cdot)$, whose density function is denoted $g($.$) . The firm i$ chooses its reservation value for idiosyncratic productivity $\bar{a}_{i t}$ : all matches below this value are destroyed. The endogenous firing rate is $\rho_{i t}=G\left(\bar{a}_{i t}\right)$ and the total separation rate is

$$
\rho_{i t}=\rho^{*}+\left(1-\rho^{*}\right) G\left(\bar{a}_{i t}\right)
$$

where $\rho^{*}$ is the exogenous firing rate. The survival rate for both exogenous and endogenous separation processes is $\left(1-\rho_{i t}\right)$.

The aggregate matching function is $m\left(u_{t}, v_{t}\right)=\bar{m} u_{t}^{\gamma} v_{t}^{1-\gamma}$ with $v_{t}=\int_{0}^{1} v_{i t} d i$, which represents the mass of vacancies posted by all firms with $v_{i t}$ being the mass of vacancies posted by the firm $i$, and $u_{t}$ being the mass of unemployed workers. $\theta_{t}=v_{t} / u_{t}$ is the labour market tightness with $q\left(\theta_{t}\right)=m\left(u_{t}, v_{t}\right) / v_{t}=m\left(1 / \theta_{t}, 1\right)$ being the probability that a vacancy will be filled in the next period.

The employment of firm $i$ is denoted $n_{i t}$, and is the sum of the employment masses over the range of admissible productivity levels $a \in\left[\bar{a}_{i t}, \infty[\right.$

$$
n_{i t}=\int_{\bar{a}_{i t}}^{\infty} n_{i t}(a) d a
$$

where $n_{i t}(a)$ is the mass of worker-job with productivity $a$. The derivatives of the output and employment of firm $i$ with respect to $n_{i t}(a)$ will be used to define the firm's contribution to the Nash bargaining process on wages. During the bargaining process, the firm can decide to keep or not the marginal worker of productivity $a$ during the bargaining process. For admissible values of $a \geq \bar{a}_{i t}$, all bargaining processes lead to wages that are accepted by both the firm and the workers and the distribution of $n_{i t}(a)$ depends on the endogenous variables $\left\{\bar{a}_{i t}, n_{i t}\right\}$ and the exogenous density function $g(a)$. 
Indeed, the firm chooses the lower bound of productivity, $\bar{a}_{i t}$, and the total number of matches, $n_{i t}$, through its supply of vacancies, $v_{i t}$, but it does not choose the allocation of workers within the range of admissible productivity levels $\left[\bar{a}_{i t}, \infty\left[\right.\right.$, which is imposed exogenously. For $a^{\prime}>a^{\prime \prime}>\bar{a}_{i t}$, the firm cannot control the relative sizes of the masses of matches, denoted $n_{i t}\left(a^{\prime}\right)$ and $n_{i t}\left(a^{\prime \prime}\right)$, even if it would be profitable to substitute $n_{i t}\left(a^{\prime \prime}\right)$ for $n_{i t}\left(a^{\prime}\right)$. The distribution of matches between $\left[\bar{a}_{i t}, \infty[\right.$ is non-persistent and is entirely determined by the exogenous power density function $g(\cdot)$. The mass of matches of productivity $a$ is given by

$$
n_{i t}(a)=\frac{g(a)}{1-G\left(\bar{a}_{i t}\right)} n_{i t}, \text { for } a \in\left[\bar{a}_{i t}, \infty\right]
$$

where $n_{i t}$ is the aggregate employment and $g(a) /\left[1-G\left(\bar{a}_{i t}\right)\right]$ the power density function of $a$ for the (endogenous) range of admissible values for the idiosyncratic productivity.

The evolution of firm $i$ employment level is

$$
n_{i t+1}=\left(1-\rho_{i t+1}\right)\left(n_{i t}+v_{i t} q\left(\theta_{t}\right)\right)
$$

in which we assume that each firm gets a linear proportion $v_{i t} / v_{t}$ of the total matches $m\left(u_{t}, v_{t}\right)$. Idiosyncratic productivity shocks are the same for both newly created $\left(v_{i t} q\left(\theta_{t}\right)\right)$ and existing jobs $\left(n_{i t}\right)$, and therefore the same proportion $\rho_{i t+1}$ of jobs is destroyed at the beginning of the period $t+1$.

Total output of firm $i$ at time $t$ is

$$
y_{i t}=f\left(h_{i t}\right)=h_{i t}^{\alpha}
$$

with $0 \leq \alpha<1$ and $h_{i t}$ is the amount of effective labor input:

$$
h_{i t}=h\left(n_{i t}, \bar{a}_{i t}\right)=z \int_{\bar{a}_{i t}}^{\infty} a n_{i t}(a) d a=z n_{i t} \int_{\bar{a}_{i t}}^{\infty} a \frac{g(a)}{1-G\left(\bar{a}_{i t}\right)} d a
$$

with $z$ being the productivity of workers, which is common to all firms. 


\subsection{The Firm's Program}

The discounted sum of the profits of firm $i$ is

$$
\begin{aligned}
\Pi_{i t} & =\sum_{k=t}^{\infty} \beta^{k-t}\left\{\left(z \int_{\bar{a}_{i k}}^{\infty} a n_{i k}(a) d a\right)^{\alpha}-\int_{\bar{a}_{i k}}^{\infty} \widetilde{w}_{i k}\left(\left\{n_{i k}\left(a^{\prime}\right)\right\}_{a^{\prime}=\bar{a}_{i k}}^{a^{\prime}=\infty}, \bar{a}_{i k}, a\right) n_{i k}(a) d a-\kappa v_{i k}\right\} \\
& -\sum_{k=t-1}^{\infty} \beta^{k+1-t} \lambda_{i k+1}\left\{\int_{\bar{a}_{i k+1}}^{\infty} n_{i k+1}(a) d a-\left(1-\rho^{*}\right)\left[1-G\left(\bar{a}_{i k+1}\right)\right]\left(\int_{\bar{a}_{i k}}^{\infty} n_{i k}(a) d a+v_{i k} q\left(\theta_{k}\right)\right)\right\}
\end{aligned}
$$

where $\beta_{k, t}=\beta^{(k-t)}$ is the discount factor at date $k$ (the reference date is denoted $t$ ) and $\lambda_{i k+1}$ is the multiplier of the employment evolution constraint. Two costs are taken into account. First, the recruitment of new workers is costly and the per-period cost of a vacancy is $\kappa$. Second, the wage for a match of productivity $a$ is denoted $\widetilde{w}_{i k}(\cdot)$ and depends on the distribution of employment in the firm $\left\{n_{i k}\left(a^{\prime}\right)\right\}_{a^{\prime}=\bar{a}_{i k}}^{a^{\prime}}$, the current value for the reservation productivity $\left\{\bar{a}_{i k}\right\}$, and the value for the idiosyncratic productivity $a$. According to the definition of $n_{i t}(a)$ given in equation (3), the distribution of employment depends on the two endogenous variables $\left\{n_{i t}, \bar{a}_{i t}\right\}$ and on the specification of the exogenous power density function $g(\cdot)$. We use this property and postulate a functional form of individual wage whose arguments are simply $\left\{n_{i t}, \bar{a}_{i t}, a\right\}$ rather than the entire distribution of employment $\left\{n_{i t}\left(a^{\prime}\right)\right\}_{a^{\prime}=\bar{a}_{i k}}^{a^{\prime}=\infty}$.

Claim 1 The wage for the value a of the idiosyncratic productivity shock in firm $i$ is a function of the two endogenous variables $\left\{n_{i t}, \bar{a}_{i t}\right\}$ and writes as follows

$$
\widetilde{w}_{i t}\left(\left\{n_{i t}\left(a^{\prime}\right)\right\}_{a^{\prime}=\bar{a}_{i k}}^{a^{\prime}=\infty}, \bar{a}_{i t}, a\right)=\widetilde{w}_{i t}\left(\left\{\frac{g\left(a^{\prime}\right)}{1-G\left(\bar{a}_{i t}\right)} n_{i t}\right\}_{a^{\prime}=\bar{a}_{i t}}^{a^{\prime}=\infty}, \bar{a}_{i t}, a\right)=\widetilde{w}_{i t}\left(n_{i t}, \bar{a}_{i t}, a\right)
$$

This postulate for the individual wage function uses the property (3) and is consistent with the intrafirm bargaining approach; because the firm does not decide on the whole distribution of matches, but only on the mass of matches and the lower bound of the idiosyncratic productivity level, the wage of a worker with a productivity of $a$ does not depend on the distribution of jobs within the range of productivity $\left[\bar{a}_{i t}, \infty[\right.$ for a given firm size. We will further prove that this specification of the individual wage is consistent with the outcome of the Nash bargaining process. Therefore, the wage bill is

$$
\int_{\bar{a}_{i k}}^{\infty} \widetilde{w}_{i k}\left(\left\{n_{i k}\left(a^{\prime}\right)\right\}_{a^{\prime}=\bar{a}_{i k}}^{a^{\prime}=\infty}, \bar{a}_{i k}, a\right) n_{i k}(a) d a=w_{i t}\left(n_{i t}, \bar{a}_{i t}\right) n_{i t}
$$


where $w_{i t}\left(n_{i t}, \bar{a}_{i t}\right)$ is the average wage bill per employee defined by

$$
w_{i t}\left(n_{i t}, \bar{a}_{i t}\right)=\int_{\bar{a}_{i t}}^{\infty} \widetilde{w}_{i t}\left(n_{i t}, \bar{a}_{i t}, a\right) \frac{g(a)}{1-G\left(\bar{a}_{i t}\right)} d a
$$

Once again, this expression only depends on the variables $n_{i t}$ and $\bar{a}_{i t}$ due to the intrafirm bargaining assumption.

Finally, the firm's problem is to choose its supply of vacancies $v_{i t}$, its reservation value for idiosyncratic productivity $\bar{a}_{i t}$, and its employment level $n_{i t}$ to maximise the discounted sum of profits defined by (7) under conditions (2), (3), (5), (6), and (10), that is

$$
\begin{aligned}
\max _{v_{i t}, n_{i t}, \bar{a}_{i t+1}} \Pi_{i t}= & \sum_{k=t}^{\infty} \beta^{k-t}\left\{\left(z n_{i k} \int_{\bar{a}_{i k}}^{\infty} a \frac{g(a)}{1-G\left(\bar{a}_{i k}\right)} d a\right)^{\alpha}-w_{i k}\left(n_{i k}, \bar{a}_{i k}\right) n_{i k}-\kappa v_{i k}\right\} \\
& -\sum_{k=t-1}^{\infty} \beta^{k+1-t} \lambda_{i k+1}\left\{n_{i k+1}-\left(1-\rho^{*}\right)\left[1-G\left(\bar{a}_{i k+1}\right)\right]\left(n_{i k}+v_{i k} q\left(\theta_{k}\right)\right)\right\}
\end{aligned}
$$

\subsection{The Asset Value of Jobs}

To solve the Nash bargaining program, we define the asset value of a job with productivity $a$ for firm $i$

$$
\begin{aligned}
J_{i t}(a)= & z a \alpha h\left(n_{i t}, \bar{a}_{i t}\right)^{\alpha-1}-\widetilde{w}_{i t}\left(n_{i t}, \bar{a}_{i t}, a\right) \\
& -\underbrace{\int_{\bar{a}_{i t}}^{\infty} \frac{\partial \widetilde{w}_{i t}\left(n_{i t}, \bar{a}_{i t}, a^{\prime}\right)}{\partial n_{i t}(a)} n_{i t}\left(a^{\prime}\right) d a^{\prime}}_{\text {Intrafirm }} \\
& +\beta\left[\left(1-\rho_{i t+1}\right) \int_{\bar{a}_{i t+1}}^{\infty} J_{i t+1}(a) \frac{g(a)}{1-G\left(\bar{a}_{i t+1}\right)} d a\right]
\end{aligned}
$$

where the first term is the marginal productivity of the match of productivity $a$, see (5)-(6), the second term is the individual wage, the third term is associated with the "intrafirm effect", and the last term is the discounted value for the match. With probability $\left(1-\rho_{i t+1}\right)$, the match survives and the firm gets the average value of future matches.

The third term, associated with the "intrafirm effect", accounts for the impact of the marginal worker of productivity $a$ on all the individual wages paid by the firm $i$. Under conditions (2) and (3), and given 
the expressions (8) for the individual wage and (10) for the average wage bill, this term becomes

$$
\int_{\bar{a}_{i t}}^{\infty} \frac{\partial \widetilde{w}_{i t}\left(n_{i t}, \bar{a}_{i t}, \bar{a}_{i t+1}, a^{\prime}\right)}{\partial n_{i t}(a)} n_{i t}\left(a^{\prime}\right) d a^{\prime}=w_{i t}^{1}\left(n_{i t}, \bar{a}_{i t}\right) n_{i t}, \quad \forall a \in\left[\bar{a}_{i t},+\infty[\right.
$$

that is the product of the marginal impact of employment on the average wage bill and the firm's employment

level - see Appendix A.1 for details. It is interesting to note that this expression does not depend on the idiosyncratic productivity level $a$. This crucial property of the model follows directly from the postulate on wage distribution (8). In the Nash bargaining program, we will use the following expression for the asset value of a job with productivity $a$ for firm $i$

$$
\begin{aligned}
J_{i t}(a)= & z a \alpha h\left(n_{i t}, \bar{a}_{i t}\right)^{\alpha-1}-\widetilde{w}_{i t}\left(n_{i t}, \bar{a}_{i t}, a\right)-w_{i t}^{1}\left(n_{i t}, \bar{a}_{i t}\right) n_{i t} \\
& +\beta\left[\left(1-\rho_{i t+1}\right) \int_{\bar{a}_{i t+1}}^{\infty} J_{i t+1}(a) \frac{g(a)}{1-G\left(\bar{a}_{i t+1}\right)} d a\right]
\end{aligned}
$$

using (12) and (13).

\subsection{The Nash Bargaining on Wages}

To solve the Nash bargaining process on wages, we first define the value of being employed or unemployed to a worker. The asset value of a match for a worker with productivity $a$ is denoted $W_{i t}(a)$ and defined by

$$
\begin{aligned}
W_{i t}(a)= & \widetilde{w}_{i t}\left(n_{i t}, \bar{a}_{i t}, a\right)+\beta\left(1-\rho^{*}\right)\left[1-G\left(\bar{a}_{i t+1}\right)\right] \int_{\bar{a}_{i t+1}}^{\infty} W_{i t+1}(a) \frac{g(a)}{1-G\left(\bar{a}_{i t+1}\right)} d a \\
& +\beta\left[\rho^{*}+\left(1-\rho^{*}\right) G\left(\bar{a}_{i t+1}\right)\right] U_{t+1}
\end{aligned}
$$

where $U_{t}$ is the expected return of being unemployed and is defined by

$$
U_{t}=b+\beta \theta_{t} q\left(\theta_{t}\right)\left(1-\boldsymbol{\rho}_{t+1}\right) \int_{\overline{\mathbf{a}}_{t+1}}^{\infty} W_{t+1}(a) \frac{g(a)}{1-G\left(\overline{\mathbf{a}}_{t+1}\right)} d a+\left[1-\theta_{t} q\left(\theta_{t}\right)\left(1-\boldsymbol{\rho}_{t+1}\right)\right] \beta U_{t+1}
$$

where $b$ measures home production and the variables in bold show the average values of these variables in the economy. The wage solution of the bargaining program within firm $i$ is

$$
W_{i t}(a)-U_{t}=\frac{\chi}{1-\chi} J_{i t}(a)
$$

where $\chi$ is the bargaining power for the worker and $(1-\chi)$ is the bargaining power for the firm. 


\section{Equilibrium}

In this section, we first present the wage solution of the intrafirm bargaining process, then we show that it is consistent with our postulate for the individual wage specification, and then we discuss our findings. We then define the equilibrium and provide some conditions for its efficiency.

\subsection{The Wage Solution}

\subsubsection{The Resolution of the Intrafirm Bargaining Process}

The solution of the Nash program (17) is the individual wage function $\widetilde{w}_{i t}(\cdot)$ that satisfies

$$
\widetilde{w}_{i t}\left(n_{i t}, \bar{a}_{i t}, a\right)+\chi w_{i t}^{1}\left(n_{i t}, \bar{a}_{i t}\right) n_{i t}=(1-\chi) b+\chi \kappa \theta_{t}+\chi z a \alpha h\left(n_{i t}, \bar{a}_{i t}\right)^{\alpha-1}
$$

It should be noted that the implicit functional form of $\widetilde{w}_{i t}$ deduced from equation (18) is consistent with our postulate on the wage distribution (8). As is common in intrafirm bargaining models, there is a partial derivative of the wage function with respect to employment in the equation solution of the bargaining process. However, in our setup the partial derivative term is the derivative of the average wage $w_{i t}(\cdot)$ with respect to employment, while the interest variable is the individual wage $\widetilde{w}_{i t}(\cdot)$. We must therefore first compute the average wage by aggregating the wages defined by the equation (18) using the definition (10) of the average wage. The average wage solution of the Nash program (17) solves the partial differential equation

$$
w_{i t}\left(n_{i t}, \bar{a}_{i t}\right)=(1-\chi) b+\chi \kappa \theta_{t}+\chi\left[\frac{\partial f\left(h\left(n_{i t}, \bar{a}_{i t}\right)\right)}{\partial n_{i t}}-w_{i t}^{1}\left(n_{i t}, \bar{a}_{i t}\right) n_{i t}\right]
$$

whose solution is

$$
w_{i t}\left(n_{i t}, \bar{a}_{i t}\right)=(1-\chi) b+\chi \kappa \theta_{t}+\frac{\alpha \chi}{1-\chi(1-\alpha)} \frac{h\left(n_{i t}, \bar{a}_{i t}\right)^{\alpha}}{n_{i t}}
$$

This expression for the average wage gives rise to the following equation for the individual wage solution of the equation (18)

$$
\widetilde{w}_{i t}\left(n_{i t}, \bar{a}_{i t}, a\right)=(1-\chi) b+\chi \kappa \theta_{t}+\chi\left[\frac{\partial f\left(h\left(n_{i t}, \bar{a}_{i t}\right)\right)}{\partial n_{i t}(a)}-\frac{\chi(\alpha-1)}{1-\chi(1-\alpha)} \frac{\partial f\left(h\left(n_{i t}, \bar{a}_{i t}\right)\right)}{\partial n_{i t}}\right]
$$




\subsubsection{The Impact of Firm's Decisions on Wages}

The average wage is affected by the firm's hiring and firing decisions. The partial derivatives of the average wage function given by equation (20) with respect to $\bar{a}_{i t}$ and $n_{i t}$ are

$$
\begin{aligned}
w_{i t}^{1}\left(n_{i t}, \bar{a}_{i t}\right) & =-\frac{\alpha \chi(1-\alpha)}{1-\chi(1-\alpha)} \frac{h\left(n_{i t}, \bar{a}_{i t}\right)^{\alpha}}{n_{i t}^{2}} \leq 0 \\
w_{i t}^{2}\left(n_{i t}, \bar{a}_{i t}\right) & =\frac{\alpha^{2} \chi}{1-\chi(1-\alpha)} \frac{g\left(\bar{a}_{i t}\right)}{1-G\left(\bar{a}_{i t}\right)} \frac{h\left(n_{i t}, \bar{a}_{i t}\right)^{\alpha}}{n_{i t}}\left[1-\frac{\bar{a}_{i t}}{\int_{\bar{a}_{i t}}^{\infty} a \frac{g(a)}{1-G\left(\bar{a}_{i t}\right)} d a}\right]>0
\end{aligned}
$$

The negative effect of employment on the average wage measured by $w_{i t}^{1}(\cdot)$ corresponds to the classical "overemployment" result, originally described by Stole and Zwiebel (1996a,b) and afterwards restated in the context of matching frictions by Smith (1999) and Cahuc et al. (2008). These authors showed that this effect vanishes if the technology is linear $(\alpha=1)$. The positive impact of the productivity reservation on the average wage measured by $w_{i t}^{2}(\cdot)$ is the sum of two effects:

$$
\begin{aligned}
w_{i t}^{2}\left(n_{i t}, \bar{a}_{i t}\right)= & \underbrace{\frac{g\left(\bar{a}_{i t}\right)}{1-G\left(\bar{a}_{i t}\right)}\left[w_{i t}\left(n_{i t}, \bar{a}_{i t}\right)-\widetilde{w}_{i t}\left(n_{i t}, \bar{a}_{i t}, \bar{a}_{i t}\right)\right.}_{\text {impact on the average quality }}] \\
& +\underbrace{\int_{\bar{a}_{i t}}^{\infty} \widetilde{w}_{i t}^{2}\left(n_{i t}, \bar{a}_{i t}, a\right) \frac{g(a)}{1-G\left(\bar{a}_{i t}\right)} d a}_{\text {impact on the individual wages }}
\end{aligned}
$$

The first effect is associated with the "average quality" of matches and exists even if the production function is linear as in Krause and Lubik (2007). ${ }^{12}$ Increasing $\bar{a}_{i t}$ improves the average quality of the selected matches and therefore improves the average wage paid by the firm: this effect would hold without the intrafirm bargaining assumption. It is easy to see that this first term positively contributes to the impact of the productivity reservation on the average wage. In our specific setup, this first effect is augmented by a second one linked to the impact of the productivity reservation $\bar{a}_{i t}$ on the individual wage $\widetilde{w}_{i t}$, which results directly from the intrafirm bargaining assumption. Using definition (21), we deduce that the contribution

\footnotetext{
${ }^{12}$ In Krause and Lubik (2007), the linearity of the production function $(\alpha=1)$ makes the wage bill $w_{i t}$ independent of $n_{i t}$, but not of $\bar{a}_{i t}$.
} 
of this second effect to the average wage is negative:

$$
\int_{\bar{a}_{i t}}^{\infty} \widetilde{w}_{i t}^{2}\left(n_{i t}, \bar{a}_{i t}, a\right) \frac{g(a)}{1-G\left(\bar{a}_{i t}\right)} d a=-\frac{\chi \alpha(1-\alpha)(1-\chi)}{1-\chi(1-\alpha)} \frac{g\left(\bar{a}_{i t}\right)}{1-G\left(\bar{a}_{i t}\right)} \frac{h\left(n_{i t}, \bar{a}_{i t}\right)^{\alpha}}{n_{i t}}\left[1-\frac{\bar{a}_{i t}}{\int_{\bar{a}_{i t}}^{\infty} a \frac{g(a)}{1-G\left(\bar{a}_{i t}\right)} d a}\right] \leq 0
$$

An increase in $\bar{a}_{i t}$ lowers the relative productivity of an $a$-type worker and consequently reduces the average wage. Therefore, the intrafirm bargaining assumption considered in an endogenous destruction setup contributes to the mitigation of the positive effect of the productivity reservation on the average wage given by (24).

\subsubsection{Discussion}

The individual wage solution of the bargaining process given by equation (21) depends not only on the firm's employment level (as is common in intrafirm bargaining models), but also on the firm's decision on separation. This property makes our setup (based on workers' reallocation) different from other intrafirm bargaining models based on job reallocation such as that of Bertola and Caballero (1994). In these models of job reallocation, the average wage only depends on the firm's level of employment, and not on the firm's productivity threshold under which it destroys jobs or leaves the market. ${ }^{13}$ Our wage equation is also different from that of Helpman et al. (2010), who solved a static model in which the screening ability cutoff decided by the firm simultaneously determines both the quality and the number of workers. Therefore, the wage equation has only one argument in Helpman et al. (2010), namely the screening ability cutoff. The novelty of our approach is that it provides a wage equation solution of the intrafirm bargaining process that depends both on the firm's employment level and its firing rate. This property will turn out to be decisive when we will assess the efficiency of the competitive equilibrium, since we can detect two distortions in our

\footnotetext{
${ }^{13}$ Bertola and Caballero (1994) give the explicit expression for the wage in contracting firms that does not depend on firm's employment, see equation (19) in their paper, and the wage in expanding firms that depends on the firm's hiring effort, see equation (21) in their paper. For similar wage solutions in models of job reallocation see equation (11) of Bertola and Garibaldi (2001), equation (10) of Elsby and Michaels (2010), equation (9) of Koeniger and Prat (2007), and equation (22) of Fujita and Nakajima (2009).
} 
economy: the intrafirm bargaining assumption distorts both the hiring and firing decisions.

The distortion of the hiring and firing decisions could be interpreted in terms of both quantitative and qualitative effects. The quantitative effect proceeds from the impact of the quantity of matches on bargained wages and corresponds to the partial derivative (22). Because a greater number of matches contribute to a lowering of the average wage, firms are inclined to post too many vacancies and consequently the equilibrium firm size is above its optimal level. The interpretation of the quality effect associated with the reservation productivity is rather less straightforward because it has two opposing consequences. First, the firm's reservation productivity negatively affects the individual bargained wages, as shown by partial derivative (25), and, this should therefore drive firms to increase their reservation productivity. Second, the firm's reservation productivity negatively impacts on the effective labour input, defined by (6), as shown in the Appendix A.2, and should therefore drive firms to decrease their reservation productivity in order to lower the average wage; see (20). In the following sections we provide a full analysis of these two opposite effects of the reservation productivity and conclude that the second effect generally dominates the first, and intrafirm bargaining pushes firms to accept a quality of job-worker matches that is too low.

\subsection{The Efficiency of the Competitive Equilibrium}

Steady-state labour market allocations are determined by two variables: the productivity reservation and the labour market tightness $(\bar{a}, \theta)$. For given values of $(\bar{a}, \theta)$, the steady-state employment level $n(\theta, \bar{a})$ 
solution of equation (4) is ${ }^{14}$

$$
n(\theta, \bar{a})=\left[\frac{1-\left(1-\rho^{*}\right)(1-G(\bar{a}))}{\left(1-\rho^{*}\right)(1-G(\bar{a}))} \frac{1}{\bar{m} \theta^{\gamma}}+1\right]^{-1}
$$

with $n_{1}(\theta, \bar{a})>0$ and $n_{2}(\theta, \bar{a})<0$. The effective labour input $h(\bar{a}, \theta)$ is given by equations $(6)$ and $(\mathrm{n})$

$$
h(\theta, \bar{a})=z\left[\frac{1-\left(1-\rho^{*}\right)(1-G(\bar{a}))}{\left(1-\rho^{*}\right)(1-G(\bar{a}))} \frac{1}{\bar{m} \theta^{\xi}}+1\right]^{-1} \int_{\bar{a}}^{\infty} a \frac{g(a)}{1-G(\bar{a})} d a
$$

with $h_{1}(\theta, \bar{a})>0$ and $h_{2}(\theta, \bar{a})<0$. The steady-state employment level unambiguously increases with $\theta$ and decreases with $\bar{a}$. Hence, $h$ straightforwardly increases with $\theta$. The overall impact of $\bar{a}$ on the effective labour input should be ambiguous because an increase in $\bar{a}$ lowers the employment rate, but raises the average quality of matches. We show in the Appendix A.2 that the overall impact is negative. The optimal and competitive values for $(\bar{a}, \theta)$ are now defined.

Definition 1 The optimal values $\left\{\theta^{\circ}, \bar{a}^{\circ}\right\}$, solution of the social planner program described in the Appendix A.4, solve

$$
\begin{gathered}
\frac{\kappa}{\bar{m}\left(\theta^{\circ}\right)^{\xi-1}}=\beta\left(1-\rho^{*}\right)\left[1-G\left(\bar{a}^{\circ}\right)\right] \xi \alpha h\left(\theta^{\circ}, \bar{a}^{\circ}\right)^{\alpha-1} z\left(\frac{h\left(\theta^{\circ}, \bar{a}^{\circ}\right)}{z n\left(\theta^{\circ}, \bar{a}^{\circ}\right)}-\bar{a}^{\circ}\right) \\
\frac{\kappa}{\bar{m}\left(\theta^{\circ}\right)^{\xi-1}}+\xi \alpha h\left(\theta^{\circ}, \bar{a}^{\circ}\right)^{\alpha-1} z \bar{a}^{\circ}=\xi b+(1-\xi) \kappa \theta^{\circ}
\end{gathered}
$$

where the functions $h(\theta, \bar{a})$ and $n(\theta, \bar{a})$ are given by Equations $(h)$ and $(n)$. The values $\left\{\theta^{*}, \bar{a}^{*}\right\}$, solution of the competitive economy defined in Section 2, solve

$$
\frac{\kappa}{\bar{m}\left(\theta^{*}\right)^{\xi-1}}=\beta\left[\left(1-\rho^{*}\right)\left(1-G\left(\bar{a}^{*}\right)\right) \frac{(1-\chi)}{1-\chi(1-\alpha)} \alpha z h\left(\theta^{*}, \bar{a}^{*}\right)^{\alpha-1}\left(\frac{h\left(\theta^{*}, \bar{a}^{*}\right)}{z n\left(\theta^{*}, \bar{a}^{*}\right)}-\bar{a}^{*}\right)\right]
$$

\footnotetext{
${ }^{14}$ It is computed as follows The steady-state of $(4)$ is

$$
n=(1-\rho)(n+v q(\theta))
$$

The definition of the matching process implies $v q(\theta)=\bar{m} \theta^{\gamma}(1-n)$ and the definition of $\rho$ given by (1) implies $(1-\rho)=$ $\left(1-\rho^{*}\right)(1-G(\bar{a}))$. Therefore, $(26)$ becomes

$$
\begin{aligned}
n & =\frac{(1-\rho) \bar{m} \theta^{\gamma}}{1-(1-\rho)\left(1-\bar{m} \theta^{\gamma}\right)}=\frac{\bar{m} \theta^{\gamma}}{\frac{1}{(1-\rho)}-1+\bar{m} \theta^{\gamma}} \\
& =\frac{1}{\frac{1}{\bar{m} \theta \gamma}\left[\frac{1}{\left(1-\rho^{*}\right)(1-G(\bar{a}))}-1\right]+1}=\left[\frac{1-\left(1-\rho^{*}\right)(1-G(\bar{a}))}{\left(1-\rho^{*}\right)(1-G(\bar{a}))} \frac{1}{\bar{m} \theta^{\gamma}}+1\right]^{-1}
\end{aligned}
$$
}

and finally [manque qqchose ???] 


$$
\frac{\kappa}{\bar{m}\left(\theta^{*}\right)^{\xi-1}}+\frac{(1-\chi)}{1-\chi(1-\alpha)} \alpha h\left(\theta^{*}, \bar{a}^{*}\right)^{\alpha-1} z \bar{a}^{*}=(1-\chi) b+\chi \kappa \theta^{*}
$$

see the sections A.3 and A.4 of the Appendix for details of their solution.

The terms on the LHS of the Hiring equations $\left(\mathrm{H}^{*}\right)$ and $\left(\mathrm{H}^{\circ}\right)$ represent the average matching cost defined as the ratio of the per-period search $\operatorname{cost} \kappa$ to the job matching probability $\bar{m} \theta^{\xi-1}$. Equilibrium hiring equalises this average matching cost to the discounted average value of a filled job defined by the RHS term of $\left(\mathrm{H}^{*}\right)$ for competitive firms, and by the RHS term of $\left(\mathrm{H}^{\circ}\right)$ for the social planner. The discount rate is the product of the subjective discount factor $\beta$ and the job survival rate to shocks, i.e., $\left(1-\rho^{*}\right)(1-G(\bar{a}))$. The average marginal productivity of jobs has the same expression for the two equilibria, namely $\alpha z h^{\alpha-1}(h /(z n)-\bar{a})$, but the social planner considers the share $\xi$ of this productivity rather than the share $(1-\chi) /[1-\chi(1-\alpha)]$ for competitive firms. The term $[1-\chi(1-\alpha)]^{-1}$ directly results from the intrafirm bargaining mechanism.

The terms on the LHS of $\left(\mathrm{F}^{*}\right)$ and $\left(\mathrm{F}^{\circ}\right)$ represent the marginal value of the less productive job-worker match for competitive firms and the social planner respectively. Keeping this job makes it possible to save the average matching cost - the first term $(\kappa / \bar{m}) \theta^{1-\xi}$. The second terms on the LHS of $\left(\mathrm{F}^{*}\right)$ and $\left(\mathrm{F}^{\circ}\right)$ are the shares of the marginal productivity of this match, given by $\alpha h^{\alpha-1} z \bar{a}$. As for the hiring equations, these shares are not identical for the social planner (i.e., $\xi)$ and for competitive firms: $(1-\chi) /[1-\chi(1-\alpha)]$. The RHS term of $\left(\mathrm{F}^{*}\right)$ and $\left(\mathrm{F}^{\circ}\right)$ account for opportunities outside the match, which consist in $b$ the home production of unemployed workers and $\kappa \theta=p(\theta) \cdot \kappa / q(\theta)$, the product of the worker matching probability and the average matching cost. These two terms are weighted by $\xi$ for the social planner and $\chi$ for the competitive equilibrium.

Proposition 1 The competitive equilibrium is efficient when the Hosios condition holds and the production technology is linear.

Proof. Equations $\left(H^{*}\right)-\left(F^{*}\right)$ are equivalent to $\left(H^{\circ}\right)-\left(F^{\circ}\right)$ if $\alpha=1$ and the Hosios condition holds $(1-\chi)=\xi$ 
With a linear production technology, the sole distortion in the economy (namely the trading externality associated with matching function) is efficiently internalised in the labour contract if the bargaining power of agents correspond to their contribution to the trading activities; see Hosios (1990) and Pissarides (2000). Hence, the combination of intrafirm bargaining and endogenous firing decisions generates no further distortion in the linear case. The competitive equilibrium with a concave production technology is inefficient even if the Hosios conditions holds.

With a concave production technology, intrafirm bargaining prevents the labour contract from internalising trading externalities. Intrafirm bargaining creates a distortion in the economy because firms take into account the impact of the marginal worker on the total mass of bargained wages with their employees. Without intrafirm bargaining, the firm internalises the fraction $(1-\chi)$ of the marginal productivity of labour rather than $(1-\chi) /[1-\chi(1-\alpha)]$ with intrafirm bargaining. The term $[1-\chi(1-\alpha)]^{-1}$ corresponds to the inefficiency induced by intrafirm bargaining and would be equal to 1 without intrafirm bargaining. It first appears in the hiring equation $\left(\mathrm{H}^{*}\right)$ as in other models of matching and intrafirm bargaining models with exogenous separation; e.g. Smith (1999) and Cahuc et al. (2008). Firms give a higher value to the marginal worker with intrafirm bargaining and are therefore more inclined to post vacancies. The originality of our model is that this term also appears in the firing equation $\left(\mathrm{F}^{*}\right)$. The RHS term of $\left(\mathrm{F}^{*}\right)$ corresponds to the value of the match with the lowest productivity. Through the term $[1-\chi(1-\alpha)]^{-1}$, intrafirm bargaining implies that firms give a higher value to this match than they would do without intrafirm bargaining. Firms are therefore induced to accept matches with a productivity level below its optimal level. For given values of $h$ and $n$, intrafirm bargaining unambiguously promotes an increase in labour market tightness and a fall in reservation productivity. The full impact is ambiguous, however, because the variables $h$ and $n$ are also affected by variations of $\theta$ and $\bar{a}$. The use of differentiation may help to provide some further understanding of the effect of the intrafirm bargaining assumption in our model. 


\subsection{A Graphical Representation of the Equilibrium}

To characterise the equilibrium, we introduce a parameter $\varphi$ that can take two values. If $\varphi=(1-\chi)$, the solution is the outcome of the optimal equilibrium $\{\bar{a}, \bar{\theta}\}=\left\{\bar{a}^{\circ}, \bar{\theta}^{\circ}\right\}$. Otherwise $\varphi=(1-\chi) /[1-\chi(1-\alpha)]$,

and the solution is the outcome of the competitive equilibrium $\{\bar{a}, \bar{\theta}\}=\left\{\bar{a}^{*}, \bar{\theta}^{*}\right\}$. For a linear production technology and under the Hosios condition, the competitive equilibrium is optimal and is at the intersection of two decreasing curves in the plan $(\bar{a}, \theta)$. However, this may not be the case when the production technology is concave. Full details of the calculations are provided in the Appendix A.5.

The differentiation of the Hiring Curves - either in the optimal $\left(\mathrm{H}^{\circ}\right)$ or the competitive case $\left(\mathrm{H}^{*}\right)-$ yields

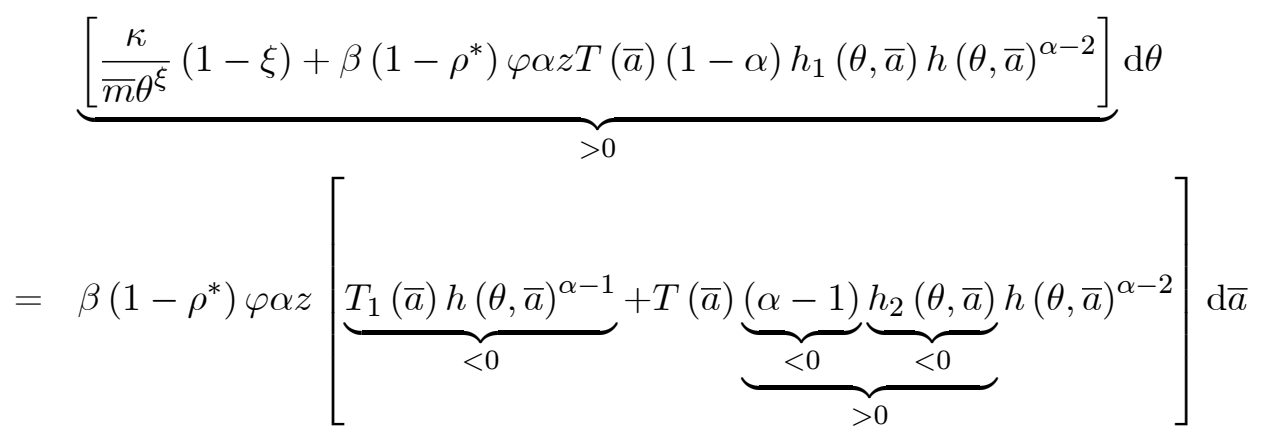

where the values of $\{\bar{a}, \bar{\theta}\}$ and $\varphi$ vary for the optimal and competitive cases as explained above and assuming that the Hosios condition still holds. When $\alpha=1$ the second bracketed term in the RHS of equation (27) is null and the slopes of the H-curves are negative. For $\alpha<1$, the sign of $\mathrm{d} \theta / \mathrm{d} \bar{a}$ depends on the relative size of the two terms on the RHS, which notably depend on the chosen functional form of $g($.$) , i.e., the$ density of productivity shocks. In the numerical section, we will show that under plausible parameterisations and assuming the log normality of idiosyncratic shocks, the overall sign of the RHS bracket term remains negative even for low values of $\alpha$. Consequently, the slopes of the H-curves appear to be negative in either case (optimal or competitive). Moreover, it is easy to see that the higher the value of $\varphi$, the higher the value of $\theta$ for a given value of $\bar{a}$ (see Appendix A.5 for further details). Hence, the intrafirm bargaining assumption causes the H-curve $\left(\mathrm{H}^{*}\right)$ to move upwards in the $(\bar{a}, \theta)$ plane, therefore contributing to overemployment for a given level of job destruction (this result confirms the standard intrafirm effect previously described in the 
literature).

If we now turn to the impact of intrafirm bargaining on the F-curves, either in the optimal $\left(\mathrm{F}^{\circ}\right)$ or the competitive case $\left(\mathrm{F}^{*}\right)$, we get

$$
\begin{gathered}
\varphi \alpha z \underbrace{\left[(\alpha-1) h_{2}(\theta, \bar{a}) h(\theta, \bar{a})^{\alpha-2} \bar{a}+h(\theta, \bar{a})^{\alpha-1}\right]}_{>0} \mathrm{~d} \bar{a} \\
=[\kappa \underbrace{\left(1-\frac{1}{\bar{m} \theta^{\xi}}\left(\frac{1-\xi}{\chi}\right)\right) \chi}_{<0}+\underbrace{(1-\alpha) \varphi \alpha z h_{1}(\theta, \bar{a}) h(\theta, \bar{a})^{\alpha-2} \bar{a}}_{>0}] \mathrm{d} \theta
\end{gathered}
$$

Once again, we find that $\mathrm{d} \theta / \mathrm{d} \bar{a}<0$ when $\alpha=1$ because the second term on the RHS of equation (28) is null. However, the role of this term if $\alpha<1$ makes the slopes of the F-curves slope rather difficult to determine. As numerical experiments will show, the sign of $\mathrm{d} \theta / \mathrm{d} \bar{a}$ can turn out to be positive when $\alpha$ is low, because the second term on the RHS dominates the first one. Moreover, the sign of $\mathrm{d} \theta / \mathrm{d} \bar{a}$ may remain ambiguous (positive for some parts of the curve and negative for others) for intermediate values of $\alpha$ : the possibility of the existence of multiple equilibria can therefore not be excluded. Throughout the numerical exercise, we will mainly work on cases where the F-curves are monotonic and where an equilibrium exists and is unique. ${ }^{15}$ Finally, the overall contribution of the intrafirm bargaining assumption can easily be identified: for a given value of $\theta$, the higher the value of $\varphi$, the lower the value of $\bar{a}$. Hence, $\varphi$ moves the F-curves to the left in the $(\bar{a}, \theta)$ plane. For a given level of market tightness, the intrafirm bargaining then contributes to a lowering of the average worker productivity. The total (i.e. simultaneously analysing the impact on the Hiring and Firing Curves) effect of intrafirm bargaining will depend on the respective (and relative) slopes of the two curves and will be analysed in the numerical experiment below.

\subsection{Numerical illustration}

In order to illustrate the normative properties of our setup, we now proceed to our numerical simulations.

This will enable us to assess quantitatively the impact of the intrafirm bargaining assumption on the labour

\footnotetext{
${ }^{15}$ We will leave the multiple equilibria analysis for further research.
} 
market tightness and the productivity reservation.

\subsubsection{Calibration}

The model period is one quarter. We set the discount factor $\beta=0.99$, making the annual interest rate close to $4 \%$. Labour income share is set to its standard value, $\alpha=0.6$. Without any loss of generality, $z$ is set to 1 . For the other calibration constraints, we follow den Haan et al. (2000). We choose an overall separation rate $\rho=0.1$ and set the exogenous firing rate of $\rho^{*}=0.068$. Hence, the endogenous separation rate is $G(\bar{a})=\left(\rho-\rho^{*}\right) /\left(1-\rho^{*}\right)=0.034$. As in den Haan et al. (2000), the average matching rate $q$ is set to 0.7 . The unemployment rate $u=1-n$ is set to 0.12 . This rate is higher than its official US empirical counterpart, since it also includes jobseeking out-of-the-labour-force workers (see Cole and Rogerson, 1999). To ensure the optimality of the 'no intrafirm bargaining' setup, we suppose that workers' and firms' shares of the bargaining surplus are similar and equal to $1 / 2$ and impose that $(1-\chi)=\xi=0.5$. Finally, we assume that the idiosyncratic productivity $a$ is iid lognormally distributed, with mean $E[\ln (a)]=0$ and standard error $\sigma_{a}=0.1$.

Table 1 gives the values of the parameters and steady-state interest variables of the intrafirm bargaining model deduced from the calibration procedure. The labour market tightness $\theta$ is derived from the dynamic equation for the employment rate. The endogenous separation rate gives $\bar{a}$ directly. Finally, the values of real cost per vacancy $\kappa$, and the home production utility flow $b$ are respectively deduced from the hiring and firing equations. The optimal values of the interest variables (here denoted $\theta^{\circ}, \bar{a}^{\circ}$ and $n^{\circ}$ ) are deduced from the no-intrafirm bargaining model through the use of equations $\left(\mathrm{H}^{\circ}\right),\left(\mathrm{F}^{\circ}\right)$ and $(\mathrm{n})$.

\subsubsection{Comparison of the Intrafirm and Optimal Equilibria}

Figure 1 provides a steady-state comparison of the hiring $(H)$ and firing $(F)$ curves in the intrafirm and optimal models. For both models, the hiring locus is decreasing and the firing locus is increasing as in Mortensen and Pissarides (1994) where the job destruction locus represents the firing one and the job 
creation locus represents the hiring one. This proves that for a standard value of the labour income share, the influence of the second term in the bracket of the RHS of equation (28) dominates that of the first term. This pattern of the locus then ensures the uniqueness of the equilibria for both the competitive and the optimal models. The labour market tightness is higher in the suboptimal intrafirm setup due to the analytically detailed upward position of the competitive hiring curve and leftward position of the competitive firing curves. Hence, our exercise confirms the higher labour market tightness effect of intrafirm bargaining as already detailed in the "exogenous destruction" literature. At the same time, the reservation productivity appears to be lower in the intrafirm case because of the relative flatness of the H-curve $(\mathrm{d} \theta / \mathrm{d} \bar{a}$ is low in absolute values). This effect on $\bar{a}$ is specific to our endogenous destruction setup and reinforces the standard over-tightness result: the overall impact of intrafirm bargaining on the employment rate (see Table 1) is positive due to the joint overposting of vacancies and the too low firing rate. The usual "overemployment" result is worsened here due to the low quality of jobs selected by firms.

Figure 2 (top panel) shows that, despite the instability of the signs of slope of the F-curve, the simultaneous effect of intrafirm bargaining on $\theta$ and $\bar{a}$ holds a variety of values of $\alpha$. For all values of $\alpha$ between 0.4 and 1, the competitive labour market allocations are characterised by excessive hiring, insufficient firing and consequently overemployment. ${ }^{16}$ To put forward the implications of the firing decision, we also consider the case of purely exogenous separations (i.e. $\bar{a}=0$ ). The middle panel of Figure 2 shows that the excessive size of firms is quite similar between the two versions of the model (with or without endogenous destruction). However, as shown by the bottom panel of Figure 2, the excess supply of vacancies is strikingly different between the two versions of the model. With endogenous destruction, the excess supply of vacancies is tiny and, for some values of $\alpha$, the supply of vacancies by firms is even too small. The excess employment is mainly the outcome of a too low average separation rate in the economy rather than an excessive supply of jobs. This picture contrasts with the case of exogenous separation where the large excess of vacancies is

\footnotetext{
${ }^{16}$ Note that in some of the intermediate values of $\alpha$ considered here (more precisely when $\alpha$ is between 0.8 and 0.9 ), the uniqueness of the equilibrium cannot be guaranteed. The figure only proposes a comparison based on a range of steady-states calibrated according to the rules described in the calibration subsection.
} 
clearly at the origin of the excessive size of firms. Therefore, our setup of endogenous worker flows provides a new view of the excessive firms' size, which is more the outcome of an insufficient amount of separations rather than an excessive supply of vacancies.

\section{Conclusion}

We have herein developed a matching and intrafirm bargaining model of the labour market to study the efficiency of hiring and firing by large firms. The novelty of our approach lies in the consideration of firms that simultaneously hire and fire workers as suggested by numerous empirical studies. This approach gives rise to specific interactions between the wage bargaining process and decisions on firing. We find a negative impact on bargained wages of the productivity threshold under which workers are fired and show how this impact is included in the firm's choice of this threshold. Because of these interactions, the equilibrium is inefficient and both hiring and firing decisions are distorted. Hence, our setup complements the standard

"overemployment" result of the intrafirm bargaining literature with exogenous job destruction: we confirm that the competitive employment rate is too high in a large firm setting with endogenous firing decisions, but also prove that the average quality of labour matches is too low in this case. Further researches should be undertaken on the usefulness of labour policy and employment legislation protection in this context. 


\section{References}

Acemoglu, D. (2001). Good Jobs versus Bad Jobs. Journal of Labor Economics 19(1), 1-21.

Bertola, G., \& Caballero, R.J. (1994). Cross-Sectional Efficiency and Labour Hoarding in a Matching Model of Unemployment. Review of Economic Studies 61(3), 435-56.

Bertola, G., \& Garibaldi, P. (2001). Wages and the Size of Firms in Dynamic Matching Models. Review of Economic Dynamics 4(2), 335-368.

Bluestone, B., Harrison, B. (1988) "The Growth of Low-Wage Employment: 1963-1986," American Economic Review 78(2), 124-128.

Burgess, S., \& Turon, H. (2010). Worker flows, job flows and unemployment in a matching model. European Economic Review 54(3), 393-408.

Burgess, S., Lane, J., Stevens, D. (2000). Job Flows, Worker Flows, and Churning. Journal of Labor Economics 18(3), 473-502.

Cahuc, P., \& Wasmer, E. (2001). Does Intrafirm Bargaining Matter in the Large Firm's Matching Model? Macroeconomic Dynamics, 5, 742-747.

Cahuc, P., Marque, F., \& Wasmer, E. (2008). A Theory of Wages and Labor Demand with Intra-firm Bargaining and Matching Frictions. International Economic Review 49(3), 943-972.

Cole, H.L., Rogerson, R. (1999). Can the Mortensen-Pissarides Matching Model Match the Business-Cycle Facts?, International Economic Review 40(4), 933-59.

Coşar, A.K., Guner, N., Tybout, J. (2008). Firm Dynamics, Job Turnover, and Wage Distributions in an Open Economy. NBER Working Paper No. 16326.

Davis, S.J., Faberman R.J., \& Haltiwanger, J.. "The Flow Approach to Labor Markets: New Data Sources and Micro-Macro Links", Journal of Economic Perspectives. Volume 20, Issue 3. 2006 
Davis, S.J., Haltiwanger, J. (1990). Gross Job Creation and Destruction: Microeconomic Evidence and Macroeconomic Implications, NBER Macroeconomics 5,123-186.

den Haan, W.J., Ramey, G., \& Watson, J. (2000). Job Destruction and Propagation of Shocks. American Economic Review 90(3), 482-498.

Diamond, P. A. (1982). Aggregate Demand Management in Search Equilibrium. Journal of Political Economy $90(5), 881-94$.

Elsby, M.W.L., \& Michaels, R. (2008). Marginal Jobs, Heterogeneous Firms, and Unemployment Flows. NBER Working Papers 13777.

Goos, M., Manning, A. (2007) Lousy and Lovely Jobs: the Rising Polarization of Work in Britain. Review of Economics and Statistics 89(1), 118-133.

Faia, E., Lechthaler, W., \& Merkl, C. (2009). Labor Selection, Turnover Costs and Optimal Monetary Policy, IZA Working papers 4322.

Fujita, S., \& Nakajima, M. (2009). Worker flows and job flows: a quantitative investigation. Working Papers 09-33, Federal Reserve Bank of Philadelphia.

Hamermesh, D.S., Hassink, W. H. J., Van Ours, J.C. (1996). Job Turnover and Labor Turnover: A taxinomy of Employment Dynamics. Annales d'Economie et de Statistique 41-42, 21-39.

Helpman, E., Itskhoki, O., \& Redding, S. (2010). Inequality and Unemployment in a Global Economy. Econometrica 78(4), 1239-1283.

Hosios, A. (1990). On the Efficiency of Matching and Related Models of Search and Unemployment. Review of Economic Studies, 57(2), 279-298.

Kiyotaki, N., Lagos, R. (2007). A Model of Job and Worker Flows, Journal of Political Economy 115(5), $770-819$.

Koeniger, W., \& Prat, J. (2007). Employment Protection, Product Market Regulation and Firm Selection. 
Economic Journal 117(521), 302-332.

Krause, M., \& Lubik, T. (2007). Does intra-firm bargaining matter for business cycle dynamics?. Deutsche Bank Discussion Paper, Series 1: Economic Studies No 17/2007.

Krause, M.U., Lopez-Salido, D.J., \& Lubik, T. A. (2008). Do search frictions matter for inflation dynamics? European Economic Review 52(8), 1464-1479.

Ljungqvist, L. (2002). How Do Layoff Costs Affect Employment? Economic Journal (2002), 829-853.

Mortensen, D. T., \& Pissarides, C.A. (1994). Job Creation and Job Destruction in the Theory of Unemployment. Review of Economic Studies 61(3), 397-415.

Pissarides, C.A. (2000). Equilibrium unemployment theory (Second edition). MIT Press.

Redding, S., (1996). The Low-skill, Low-quality Trap: Strategic Complementarities between Human Capital and R \& D. Economic Journal 106(March), 458-470.

Smith, E. (1999). Search, Concave Production, and Optimal Firm Size. Review of Economic Dynamics, $2(2), 456-471$.

Stevens, M. (1994). Labour Contracts and Efficiency in on-the-Job Training. Economic Journal 104(March), 408-419.

Stole, L., \& Zwiebel, J. (1996a). Intra-firm Bargaining under Non-binding Contracts. Review of Economic Studies, 63(3), 375-410.

Stole, L., \& Zwiebel, J. (1996b). Organizational Design and Technology Choice under Intrafirm Bargaining. American Economic Review, 86(1), 195-222.

Tripier, F. (2011). The Efficiency of Training and Hiring with Intrafirm Bargaining, Labour Economics, $18(4), 527-538$. 


\section{A Appendix}

\section{A.1 Calculus for the "intrafirm effect"}

The term associated with the "intrafirm effect" in the value function (12) is

$$
\int_{\bar{a}_{i t}}^{\infty} \frac{\partial \widetilde{w}_{i t}\left(n_{i t}, \bar{a}_{i t}, a\right)}{\partial n_{i t}(\mathbf{a})} n_{i t}(a) d a
$$

To get its expression given by (13), we proceed as follows. First, given the definition of aggregate employment

(2) we can rewrite this term as

$$
\int_{\bar{a}_{i t}}^{\infty} \frac{\partial \widetilde{w}_{i t}\left(n_{i t}, \bar{a}_{i t}, a\right)}{\partial n_{i t}} \frac{\partial n_{i t}}{\partial n_{i t}(\mathbf{a})} n_{i t}(a) d a
$$

where $\partial n_{i t} / \partial n_{i t}(\mathbf{a})=1$. Second, introducing the expression of $n_{i t}(a)$ given by (3) and the definition of the wage bill (8) lead to

$$
\left[\int_{\bar{a}_{i t}}^{\infty} \frac{\partial \widetilde{w}_{i t}\left(n_{i t}, \bar{a}_{i t}, a\right)}{\partial n_{i t}} \frac{g(a)}{1-G\left(\bar{a}_{i t}\right)} d a\right] n_{i t}
$$

because the functions $g($.$) and G($.$) do not depend on n_{i t}$, it is equivalent to

$$
\frac{\partial}{\partial n_{i t}} \underbrace{\left[\int_{\bar{a}_{i t}}^{\infty} \widetilde{w}_{i t}\left(n_{i t}, \bar{a}_{i t}, a\right) \frac{g(a)}{1-G\left(\bar{a}_{i t}\right)} d a\right]}_{w_{i t}\left(n_{i t}, \bar{a}_{i t}\right)} n_{i t}
$$

where the term in brackets is the average wage according to definition (10). Hence, the final expression given by (13): $w_{i t}^{1}\left(n_{i t}, \bar{a}_{i t}, \bar{a}_{i t+1}\right) n_{i t}$.

\section{A.2 Properties of the function $h$}

The function $h(\theta, \bar{a})$ is

$$
h(\theta, \bar{a})=z n(\theta, \bar{a}) \int_{\bar{a}}^{\infty} a \frac{g(a)}{1-G(\bar{a})} d a
$$

where the steady-state employment level $n(\bar{a}, \theta)$ is for the Cobb-Douglas matching function

$$
n(\theta, \bar{a})=\left[\frac{1-\left(1-\rho^{*}\right)(1-G(\bar{a}))}{\left(1-\rho^{*}\right)(1-G(\bar{a}))} \frac{1}{\bar{m} \theta^{\xi}}+1\right]^{-1}
$$


with $n_{1}(\theta, \bar{a})>0$ and $n_{2}(\theta, \bar{a})<0$. The partial derivatives of $h(\theta, \bar{a})$ are

$$
\begin{aligned}
& h_{1}(\theta, \bar{a})=z n_{1}(\theta, \bar{a}) \int_{\bar{a}}^{\infty} a \frac{g(a)}{1-G(\bar{a})} d a>0 \\
& h_{2}(\theta, \bar{a})=z\left[\begin{array}{c}
\underbrace{n_{2}(\theta, \bar{a})}_{\text {"quantity effect" }<0} \int_{\bar{a}}^{\infty} a \frac{g(a)}{1-G(\bar{a})} d a \\
+n(\theta, \bar{a}) \frac{g(\bar{a})}{1-G(\bar{a})} \underbrace{\left(\int_{\bar{a}}^{\infty} a \frac{g(a)}{1-G(\bar{a})} d a-\bar{a}\right)}_{\text {"quality effect" }>0}
\end{array}\right]
\end{aligned}
$$

using the definition of $n(\bar{a}, \theta)$ gives

$$
n_{2}(\theta, \bar{a})=-\frac{g(\bar{a})}{\left(1-\rho^{*}\right)(1-G(\bar{a}))^{2}} \frac{1}{\bar{m}(\theta)^{\xi}} n(\theta, \bar{a})^{2}<0
$$

therefore

$$
h_{2}(\theta, \bar{a})=z n(\theta, \bar{a}) \frac{g(\bar{a})}{1-G(\bar{a})}\left[\left(1-\frac{n(\theta, \bar{a})}{\left(1-\rho^{*}\right)(1-G(\bar{a})) \bar{m}(\theta)^{\xi}}\right) \int_{\bar{a}}^{\infty} a \frac{g(a)}{1-G(\bar{a})} d a-\bar{a}\right]<0
$$

because

$$
\left(1-\frac{n(\theta, \bar{a})}{\left(1-\rho^{*}\right)(1-G(\bar{a})) \bar{m}(\theta)^{\xi}}\right)=1-[1-\underbrace{\left(1-\rho^{*}\right)(1-G(\bar{a}))\left(1-\bar{m}(\theta)^{\xi}\right)}_{<1}]^{-1}<0
$$

The quantitative effect of $\bar{a}$ on $h$ dominates its qualitative effect.

\section{A.3 The Competitive Equilibrium}

This section defines the competitive equilibrium as the solution of the representative firm's program defined by (11). The first order conditions for the firm's program (11) are

$$
\begin{gathered}
v_{i t}: \kappa=\beta q\left(\theta_{t}\right)\left(1-\rho^{*}\right)\left(1-G\left(\bar{a}_{i t+1}\right)\right) \lambda_{i t+1} \\
n_{i t} \quad: \quad \lambda_{i t}=\alpha \frac{h\left(n_{i t}, \bar{a}_{i t}\right)^{\alpha}}{n_{i t}}-w_{i t}\left(n_{i t}, \bar{a}_{i t}\right)-n_{i t} w_{i t}^{1}\left(n_{i t}, \bar{a}_{i t}\right) \\
\quad+\beta\left[\left(1-\rho^{*}\right)\left(1-G\left(\bar{a}_{i t+1}\right)\right) \lambda_{i t+1}\right]
\end{gathered}
$$




$$
\begin{aligned}
\bar{a}_{i t+1} & : \beta\left(1-\rho^{*}\right) g\left(\bar{a}_{i t+1}\right)\left(n_{i t}+v_{i t} q\left(\theta_{t}\right)\right) \lambda_{i t+1} \\
= & \beta \frac{\partial f\left(h_{i t+1}\right)}{\partial h_{i t+1}} \frac{\partial h\left(n_{i t+1}, \bar{a}_{i t+1}\right)}{\partial \bar{a}_{i t+1}}-\beta n_{i t+1} w_{i t+1}^{2}\left(n_{i t+1}, \bar{a}_{i t+1}\right)
\end{aligned}
$$

The Hiring rule ${ }^{17}$ is obtained by combining (A.11) and (A.12)

$$
\begin{aligned}
& \frac{\kappa}{q\left(\theta_{t}\right)}=\beta\left(1-\rho^{*}\right)\left(1-G\left(\bar{a}_{i t+1}\right)\right) \\
& {\left[\alpha \frac{h\left(n_{i t+1}, \bar{a}_{i t+1}\right)^{\alpha}}{n_{i t+1}}-w_{i t+1}\left(n_{i t+1}, \bar{a}_{i t+1}\right)-n_{i t+1} w_{i t+1}^{1}\left(n_{i t+1}, \bar{a}_{i t+1}\right)+\frac{\kappa}{q\left(\theta_{t+1}\right)}\right]}
\end{aligned}
$$

which can be interpreted as follows

$$
\begin{aligned}
\qquad \underbrace{\frac{\kappa}{q\left(\theta_{t}\right)}}_{\text {Average matching costs }}=\beta \underbrace{\left(1-\rho^{*}\right)\left(1-G\left(\bar{a}_{i t+1}\right)\right)}_{\text {Prob. of match acceptance }} \\
\underbrace{\left[\begin{array}{c}
\alpha \frac{h\left(n_{i t+1}, \bar{a}_{i t+1}\right)^{\alpha}}{n_{i t+1}}-w_{i t+1}\left(n_{i t+1}, \bar{a}_{i t+1}\right) \\
-n_{i t+1} w_{i t+1}^{1}\left(n_{i t+1}, \bar{a}_{i t+1}\right)+\frac{\kappa}{q\left(\theta_{t+1}\right)}
\end{array}\right]}_{\text {Average match value }}
\end{aligned}
$$

The Firing rule ${ }^{18}$ is obtained by combining (A.13) and (4)

$$
\beta \lambda_{i t+1}\left(1-\rho^{*}\right) g\left(\bar{a}_{i t+1}\right) \frac{n_{i t+1}}{\left(1-\rho_{i t+1}\right)}=\beta \frac{\partial f\left(h_{i t+1}\right)}{\partial h_{i t+1}} \frac{\partial h\left(n_{i t+1}, \bar{a}_{i t+1}\right)}{\partial \bar{a}_{i t+1}}-\beta n_{i t+1} w_{i t+1}^{2}\left(n_{i t+1}, \bar{a}_{i t+1}\right)
$$

and then introducing the expression of $\lambda_{i t}$ given by (A.12)

$$
\lambda_{i t}=\alpha \frac{h\left(n_{i t}, \bar{a}_{i t}\right)^{\alpha}}{n_{i t}}-w_{i t}\left(n_{i t}, \bar{a}_{i t}\right)-n_{i t} w_{i t}^{1}\left(n_{i t}, \bar{a}_{i t}\right)+\frac{\kappa}{q\left(\theta_{t}\right)}
$$

and using (A.11), one obtains

$$
\begin{aligned}
& \beta\left(\begin{array}{c}
\alpha \frac{h\left(n_{i t+1}, \bar{a}_{i t+1}\right)^{\alpha}}{n_{i t+1}}-w_{i t+1}\left(n_{i t+1}, \bar{a}_{i t+1}\right) \\
-n_{i t+1} w_{i t+1}^{1}\left(n_{i t+1}, \bar{a}_{i t+1}\right)+\frac{\kappa}{q\left(\theta_{t+1}\right)}
\end{array}\right) \frac{\left(1-\rho^{*}\right) g\left(\bar{a}_{i t+1}\right) n_{i t+1}}{\left(1-\rho_{i t+1}\right)} \\
= & \beta \frac{\partial f\left(h_{i t+1}\right)}{\partial h_{i t+1}} \frac{\partial h\left(n_{i t+1}, \bar{a}_{i t+1}\right)}{\partial \bar{a}_{i t+1}}-\beta n_{i t+1} w_{i t+1}^{2}\left(n_{i t+1}, \bar{a}_{i t+1}\right)
\end{aligned}
$$

\footnotetext{
${ }^{17}$ The next equation is the counterpart of the Equation (13) of Krause and Lubick (2007).

${ }^{18}$ The next equation is the counterpart of the Equation (14) of Krause and Lubik (2007) where $\partial \rho_{i t} / \partial \bar{a}_{i t}=\left(1-\rho^{*}\right) g\left(\bar{a}_{i t}\right)$.
} 
which can be interpreted as follows

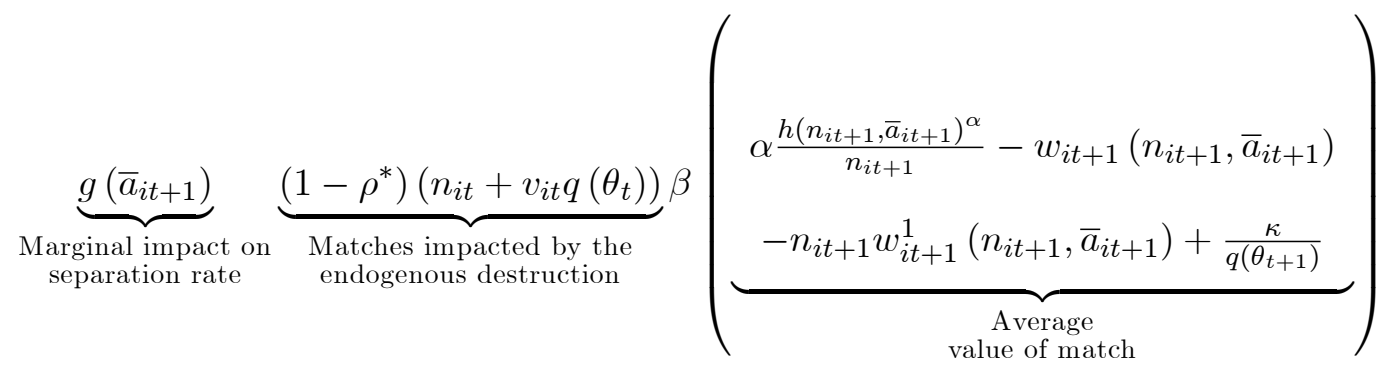

$$
\begin{aligned}
& =\beta \underbrace{\frac{\partial f\left(h_{i t+1}\right)}{\partial h_{i t+1}} \frac{\partial h\left(n_{i t+1}, \bar{a}_{i t+1}\right)}{\partial \bar{a}_{i t+1}}}_{\begin{array}{c}
\text { Marginal impact } \\
\text { on production }
\end{array}} \underbrace{-\beta n_{i t+1} w_{i t+1}^{2}\left(n_{i t+1}, \bar{a}_{i t+1}, \bar{a}_{i t+2}\right)}_{\begin{array}{c}
\text { Marginal impacts } \\
\text { on the average wage }
\end{array}}
\end{aligned}
$$

where the term on the LHS is the cost of increasing $\bar{a}$ and the term on the RHS is its benefits.

\section{A.4 The Optimal Equilibrium}

This section defines the optimal equilibrium as the solution of the social planner's program. Households are risk-neutral and discount future consumption at a rate $\beta$. Therefore, the social planner maximises the intertemporal and discounted sum of consumption, which is equal to the output minus the cost of vacancies, plus the domestic production of unemployed workers.

The social planer's program is

$$
\begin{aligned}
& \max _{\left\{v_{t}, \bar{a}_{t}, h_{t}, n_{t+1}\right\}} \Pi_{t}=\sum_{k=t}^{\infty} \beta^{k-t}\left\{h_{k}^{\alpha}+\left(1-n_{k}\right) b-\kappa v_{k}\right\} \\
& -\sum_{k=t-1}^{\infty} \beta_{k+1, t}\left\{\lambda_{k+1}\left[n_{k+1}-\left(1-\rho^{*}\right)\left(1-G\left(\bar{a}_{k+1}\right)\right)\left(n_{k}+m\left(1-n_{k}, v_{k}\right)\right)\right]\right\} \\
& -\sum_{k=t}^{\infty} \mu_{k}\left\{h_{k}-z n_{k} \int_{\bar{a}_{k}}^{\infty} a \frac{g(a)}{1-G\left(\bar{a}_{k}\right)} d a\right\}
\end{aligned}
$$

The first order conditions are

$$
\begin{aligned}
h_{t} & : \quad \alpha h_{t}^{\alpha-1}=\mu_{t} \\
v_{t} & : \quad-\kappa+\beta \lambda_{t+1}\left(1-\rho^{*}\right)\left(1-G\left(\bar{a}_{t+1}\right)\right) m_{2}\left(1-n_{t}, v_{t}\right)=0 \\
\bar{a}_{t} & : \quad \mu_{t} z \int_{\bar{a}_{t}}^{\infty}\left(a-\bar{a}_{t}\right) \frac{g(a)}{1-G\left(\bar{a}_{t}\right)} d a=\lambda_{t} \\
n_{t+1} & : \quad-b+\beta \lambda_{t+1}\left(1-\rho^{*}\right)\left(1-G\left(\bar{a}_{t+1}\right)\right)\left(1-m_{1}\left(1-n_{t}, v_{t}\right)\right)+\mu_{t} z \int_{\bar{a}_{t}}^{\infty} a \frac{g(a)}{1-G\left(\bar{a}_{t}\right)} d a=\lambda_{t}
\end{aligned}
$$


The equilibrium definition provided in Definition 1 is immediately deduced from these first order conditions.

\section{A.5 Calculus for the Graphical Representation of the Equilibria}

In order to ease the analysis of the model, we introduce a parameter $\varphi$ that can take two values. If $\varphi=(1-\chi)$, the solution is the outcome of the optimal equilibrium $\{\bar{a}, \bar{\theta}\}=\left\{\bar{a}^{\circ}, \bar{\theta}^{\circ}\right\}$. Otherwise $\varphi=$

$(1-\chi) /[1-\chi(1-\alpha)]$, and the solution is the outcome of the competitive equilibrium $\{\bar{a}, \bar{\theta}\}=\left\{\bar{a}^{*}, \bar{\theta}^{*}\right\}$.

\section{A.5.1 The Hiring Locus}

Using the parameter $\varphi$, the Hiring curves $\left(\mathrm{H}^{*}\right)$ and $\left(\mathrm{H}^{\circ}\right)$ are particular cases of

$$
\frac{\kappa}{\bar{m}(\theta)^{\xi-1}}=\beta\left(1-\rho^{*}\right) \varphi \alpha h(\theta, \bar{a})^{\alpha-1} z T(\bar{a})
$$

where the function $T(\bar{a})$ is

$$
T(\bar{a})=[1-G(\bar{a})]\left(\int_{\bar{a}}^{\infty} a \frac{g(a)}{1-G(\bar{a})} d a-\bar{a}\right)
$$

which satisfies $T(\bar{a})>0$ and $T_{1}(\bar{a})=-[1-G(\bar{a})]<0$. The differentiation of the H-curve (A.20) is

$$
\frac{\kappa}{\bar{m} \theta^{\xi}}(1-\xi) \mathrm{d} \theta=\beta\left(1-\rho^{*}\right) \varphi \alpha z\left[\begin{array}{c}
T(\bar{a})(\alpha-1) h_{1}(\theta, \bar{a}) h(\theta, \bar{a})^{\alpha-2} \mathrm{~d} \theta+T_{1}(\bar{a}) h(\theta, \bar{a})^{\alpha-1} \mathrm{~d} \bar{a} \\
+T(\bar{a})(\alpha-1) h_{2}(\theta, \bar{a}) h(\theta, \bar{a})^{\alpha-2} \mathrm{~d} \bar{a}
\end{array}\right]
$$

or equivalently

$$
\begin{gathered}
\underbrace{\left[\frac{\kappa}{\bar{m} \theta^{\xi}}(1-\xi)+\beta\left(1-\rho^{*}\right) \varphi \alpha z T(\bar{a})(1-\alpha) h_{1}(\theta, \bar{a}) h(\theta, \bar{a})^{\alpha-2}\right]}_{>0} \mathrm{~d} \theta \\
=\beta\left(1-\rho^{*}\right) \varphi \alpha z[\underbrace{T_{1}(\bar{a}) h(\theta, \bar{a})^{\alpha-1}}_{<0}+T(\bar{a}) \underbrace{(\alpha-1)}_{<0} \underbrace{h_{2}^{(\theta-1}(\theta, \bar{a})}_{<0} h(\theta, \bar{a})^{\alpha-2}] \mathrm{d} \bar{a}
\end{gathered}
$$

For $\alpha=1$, it is straightforward to show that $\mathrm{d} \theta / \mathrm{d} \bar{a}<0$ because (A.22) reduces to

$$
\underbrace{\frac{\kappa}{\bar{m} \theta^{\xi}}(1-\xi)}_{>0} \mathrm{~d} \theta=\beta\left(1-\rho^{*}\right) \varphi \alpha z \underbrace{T_{1}(\bar{a})}_{<0} \mathrm{~d} \bar{a}
$$


Rearranging the H-curve (A.20) in the following way

$$
\kappa \bar{m}(\theta)^{1-\xi} h(\theta, \bar{a})^{1-\alpha} \varphi=\beta\left(1-\rho^{*}\right)[1-G(\bar{a})] \alpha z\left(\int_{\bar{a}}^{\infty} a \frac{g(a)}{1-G(\bar{a})} d a-\bar{a}\right)
$$

we can see on the LHS of this equation that for a given value of $\bar{a}$, the higher the value of $\varphi$ the higher the value of $\theta$ because $\bar{m}(\theta)^{1-\xi} h(\theta, \bar{a})^{1-\alpha}$ is growing with $\theta$. Hence, $\varphi$ moves the H-curve upwards in the $(\bar{a}, \theta)$ plan.

\section{A.5.2 The Firing Locus}

Using the parameter $\varphi$, the Firing curves $\left(\mathrm{F}^{*}\right)$ and $\left(\mathrm{F}^{\circ}\right)$ are particular cases of

$$
\frac{\kappa}{\bar{m} \theta^{\xi-1}}=(1-\chi) b+\chi \kappa \theta-\varphi \alpha h(\theta, \bar{a})^{\alpha-1} z \bar{a}
$$

The differentiation of the F-curve (A.23) is

$$
\begin{aligned}
& \varphi \alpha z\left[(\alpha-1) h_{1}(\theta, \bar{a}) h(\theta, \bar{a})^{\alpha-2} \bar{a} \mathrm{~d} \theta+(\alpha-1) h_{2}(\theta, \bar{a}) h(\theta, \bar{a})^{\alpha-2} \bar{a} \mathrm{~d} \bar{a}+h(\theta, \bar{a})^{\alpha-1} \mathrm{~d} \bar{a}\right] \\
= & \kappa\left[1-\frac{1}{\bar{m} \theta^{\xi}}\left(\frac{1-\xi}{\chi}\right)\right] \chi \mathrm{d} \theta
\end{aligned}
$$

which gives

$$
\begin{gathered}
\varphi \alpha z \underbrace{\left[(\alpha-1) h_{2}(\theta, \bar{a}) h(\theta, \bar{a})^{\alpha-2} \bar{a}+h(\theta, \bar{a})^{\alpha-1}\right]}_{>0} \mathrm{~d} \bar{a} \\
=[\kappa \underbrace{\left(1-\frac{1}{\bar{m} \theta^{\xi}}\left(\frac{1-\xi}{\chi}\right)\right) \chi}_{<0}+\underbrace{(1-\alpha) \varphi \alpha z h_{1}(\theta, \bar{a}) h(\theta, \bar{a})^{\alpha-2} \bar{a}}_{>0}] \mathrm{d} \theta
\end{gathered}
$$

The sign of the bracketed term on the RHS cannot be deduced analytically because it depends on the specific functional form of $G()$. Nevertheless, we note that for $\alpha=1$ and when the Hosios condition holds, we obtain

$$
\frac{\mathrm{d} \theta}{\mathrm{d} \bar{a}}=\frac{\varphi \alpha z}{\left[\kappa\left(1-\frac{1}{\bar{m} \theta^{\xi}}\right) \chi\right]}<0
$$

and the slope is unambiguously negative. However, the sign of the slope of the F-curve (A.23) may change when $\alpha<1$ because the size of the second term on the RHS of equation (A.24) grows as $\alpha$ reduces. Indeed, 
numerical experiments demonstrate that $\mathrm{d} \theta / \mathrm{d} \bar{a}>0$ when $\alpha$ is sufficiently low. If we turn now to the role of $\varphi$ by rewriting the F-curve (A.23) in the following manner

$$
\varphi \alpha h(\theta, \bar{a})^{\alpha-1} z \bar{a}=(1-\chi) b+\chi \kappa \theta-\frac{\kappa}{\bar{m} \theta^{\xi-1}}
$$

we deduce that for a given value of $\theta$, the higher the value of $\varphi$, the lower the value of $\bar{a}$. Hence, $\varphi$ moves the F-curve to the left in the $(\bar{a}, \theta)$ plan. 


\section{B Table and Figures}

Table 1: Calibration and steady-state equilibria

\begin{tabular}{c}
\hline \hline Parameters $\quad \beta=0.99, \chi=0.5, \alpha=0.6, \gamma=0.5,, \sigma_{0}=0.1$ \\
$\rho^{*}=0.068, \bar{m}=0.75, \kappa=0.04, b=0.72$
\end{tabular}




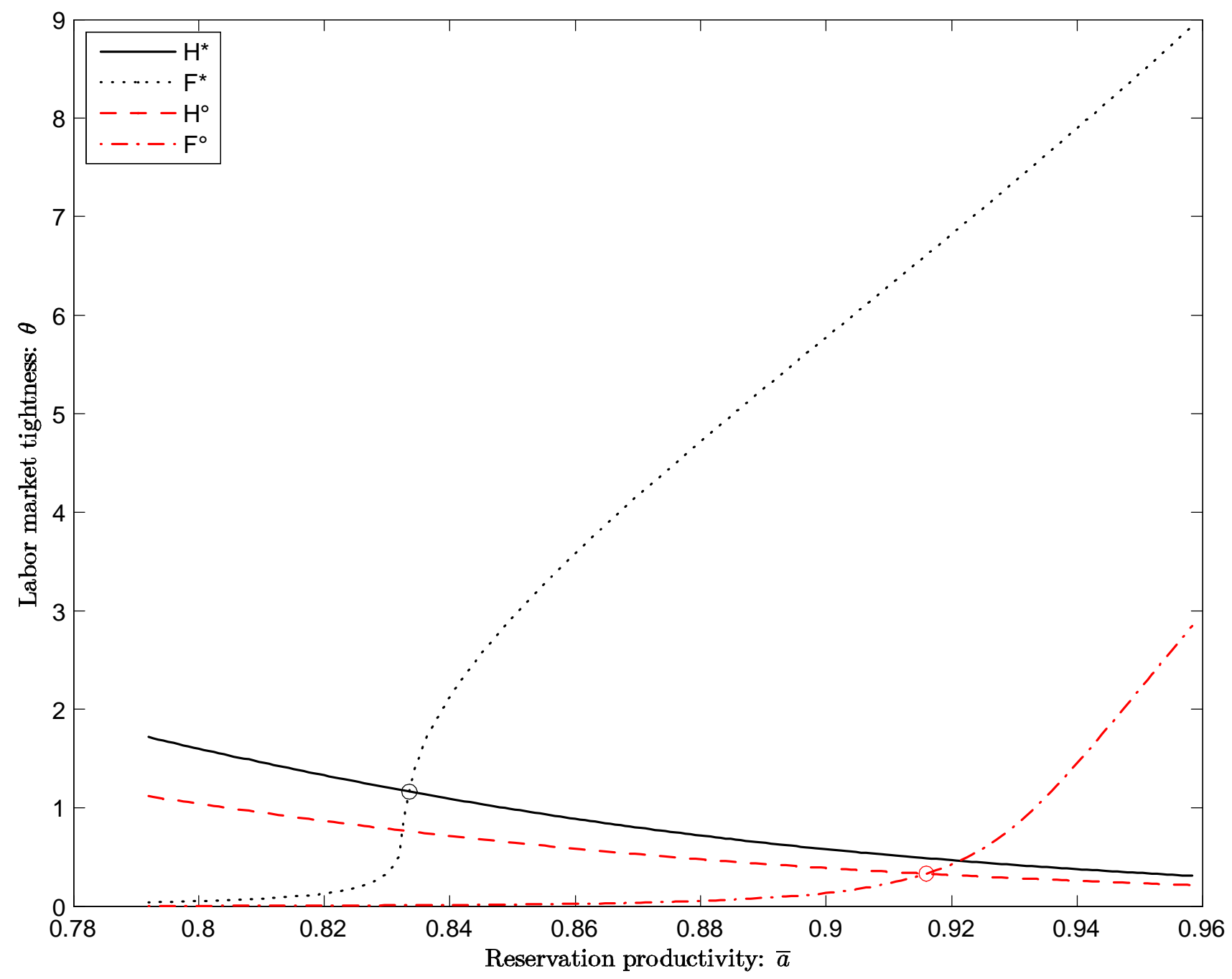

Figure 1: Hiring and firing curves for the competitive and optimal equilibria $(\alpha=0.60)$. 
Relative deviation with respect to the optimal case with endogenous separation

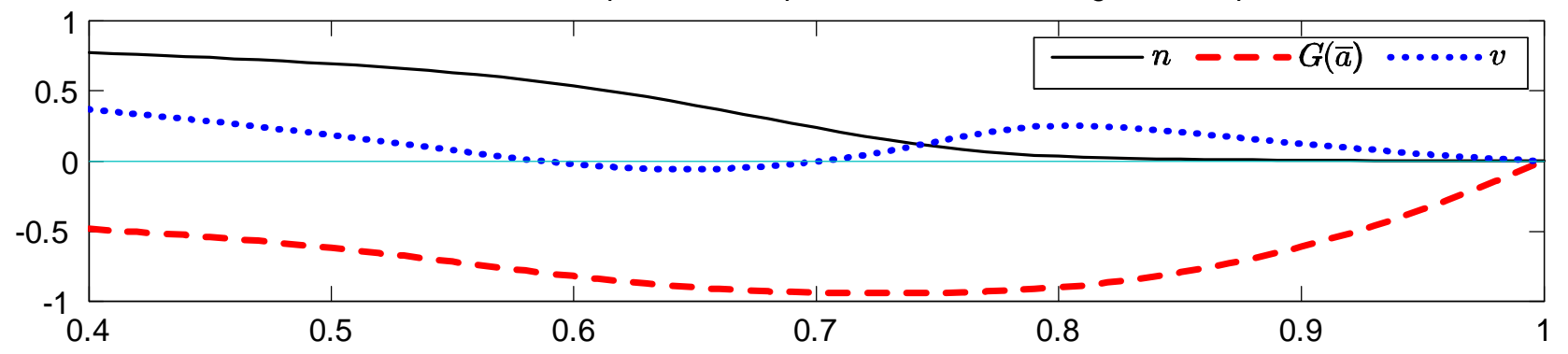

Relative deviation with respect to the optimal case with endogenous or exogenous separation

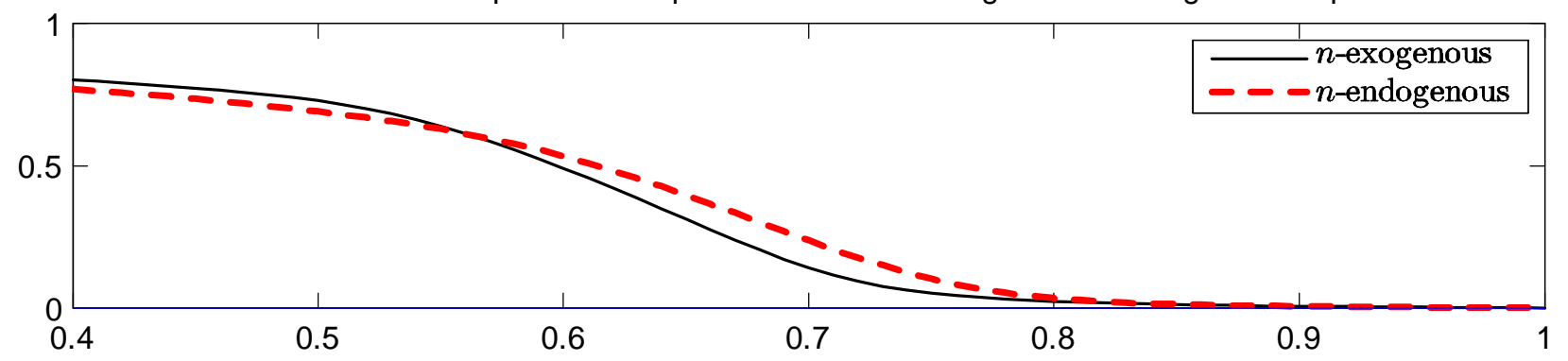

Relative deviation with respect to the optimal case with endogenous or exogenous separation

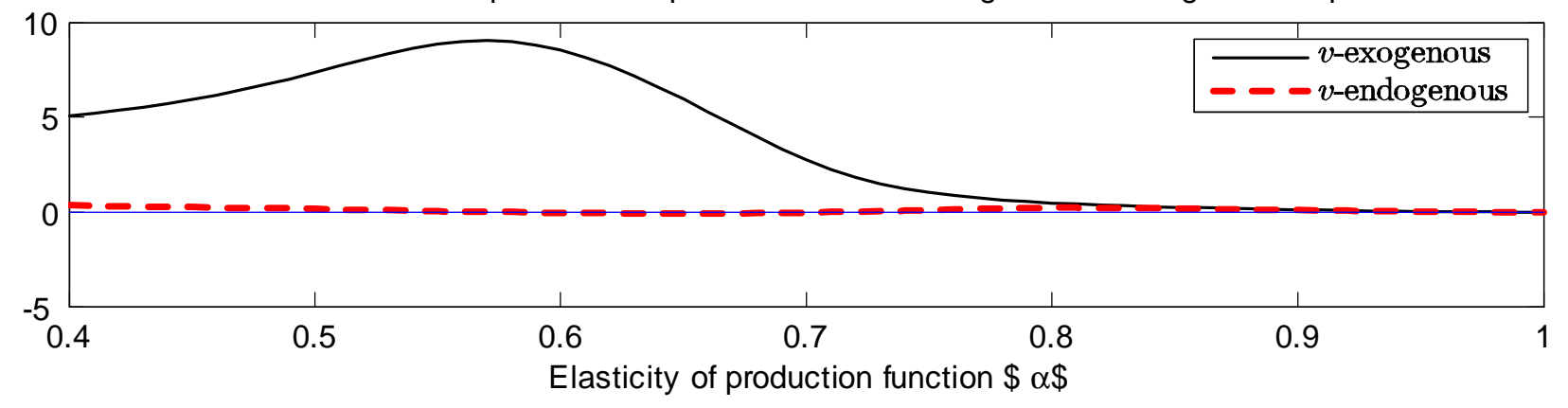

Figure 2: Relative deviation between the competitive and the optimal allocations on the labor market 